\title{
Relationship between Trunk Impairment and Upper Extremity Function, and Its Impact on Activities of Daily Living in Chronic Stroke Survivors
}

\author{
Ludhiya Baby ${ }^{1}$, Anoop Joy ${ }^{2}$, Ranjith $\mathrm{KV}^{3}$ \\ ${ }^{1,2}$ MPT Scholar, Department of Physiotherapy, Rajiv Gandhi University of Health Sciences, Bangalore, \\ Karnataka, India. \\ ${ }^{3}$ Lecturer, Department of Physiotherapy, Rajiv Gandhi University of Health Sciences, Bangalore, Karnataka,
} India.

Corresponding Author: Anoop Joy

\begin{abstract}
Background: Stroke often leads to significant impairment of trunk and upper extremity functions, which is associated with decreased quality of life and functional performance in all domains. Trunk stability and control is considered to be a prerequisite for upper extremity function in stroke survivors. Therefore, it is important to evaluate the relationship between trunk impairment and upper extremity function in stroke survivors which may help in improving their ADL's by giving proper treatment.
\end{abstract}

Methods: 20 chronic stroke survivors with age group between 40-80 years were included in this study. Trunk impairment, upper extremity function and activities of daily living of all the participants were determined using trunk impairment scale, Chedoke arm and hand activity inventory scale (version 8) and functional independence measure - motor scoring scale.

Results: Using Karl Pearson's Correlation coefficient, moderate positive correlation was observed between TIS and CAHAI-8. Strong positive correlation was noted between TIS and FIM-M, whereas, moderate positive correlation was noted between CAHAI-8 and FIM-M which was found to be highly statistically significant.

Conclusion: Our study concludes that, a moderate positive correlation exists between trunk impairment and upper extremity function in chronic stroke survivors. The study also reveals that, both trunk impairment and upper extremity function has strong and moderate correlation on their activities of daily living.

Keywords: Stroke, trunk function, paretic arm, functional performance, stroke rehabilitation.

\section{INTRODUCTION}

Stroke is defined as a clinical syndrome characterised by "rapidly developing clinical signs of focal (or global) disturbance of cerebral function, with symptoms lasting 24 hours or longer or leading to death, with no apparent cause other than of vascular origin" ${ }^{[1,2]}$. It has three phases; the initial phase or acute stroke, subacute phase and chronic phase. Chronic stroke continues from months to years following stroke and the patient may or may not complete his/her life within this phase. ${ }^{[3]}$ Stroke continues to have a great impact on public health as a major cause of long-term disability, with certain motor deficits as experienced by approximately $90 \%$ of stroke survivors. ${ }^{[4]}$ Many stroke survivors encounter complex neurologic deficits, muscle weakness and sensory dysfunction, leading to poor movement quality, and cognitive impairments in contralateral upper limbs and lower limbs along with significant affection of trunk. ${ }^{[5]}$

Trunk performance has been found to be an important predictor of functional independence after stroke. ${ }^{[6]}$ Some studies reported that trunk control or sitting balance 
in patients at the early stage of stroke could predict their ADL outcome in the late stages of stroke. ${ }^{[7,8]}$ Many stroke survivors suffer from insufficient trunk control, affecting their functional ability in activities like, sit to stand, standing, walking and in reach out activities. ${ }^{[3]}$ When healthy individuals try to reach out objects beyond their arm length, the trunk begins to move slightly before or simultaneously with their hand, but in stroke patients with trunk impairment, trunk begins to move only after the hand reaches its peak velocity. This could increase the risk of fall and functional limitation in stroke survivors. Thus, trunk play an integral role in postural stabilization by supporting controlled movement of upper extremity during task performance. ${ }^{[9]}$

Stroke often leads to significant impairment of upper extremity function and is associated with decreased quality of life and functional performance in all domains. ${ }^{[10]}$ The upper extremity plays a vital role in the performance of activities of daily living as over $50 \%$ of $\mathrm{ADL}$ tasks requires reach and grasp ability. ${ }^{[1]}$ Studies shows that, about $85 \%$ of the stroke patients experience partial paralysis of the upper limb and more over $50 \%$ of them shows impaired upper limb and hand function in the chronic phase. ${ }^{[2]}$ When the upper limb functions of the stroke patients get affected, it causes difficulty to perform activities of daily living. In order to reach the target, the upper extremity should be stretched along with the shoulder and elbow to increase the length of the arm's leverage. This will cause alteration in the center of gravity of the body. So, in order to maintain balance and posture while moving the upper extremity, a proper trunk stability is required. In stroke survivors with reduced trunk stability, the upper extremity function may be reduced due to reduced postural control. [12,13] Regaining the optimal level of use of the damaged upper limbs is important, as it is essential for daily life activities.

Many of the stroke survivors does not regain functional use of the paretic arm, which can cause limitation for participation in community life. ${ }^{[14]}$ These activity limitations experienced post-stroke, may include both basic and instrumental activities of daily living. [15] This impairment may cause difficulty to perform functional activities such as eating, toileting, dressing and washing, which is considered as the fundamental principles for daily activities and also commonly compromise certain activities within their communities and to run their households. Limitations in activities are the major challenge experienced to patients who have experienced stroke at least once in their life. Studies shows that, trunk stability and control is considered to be a prerequisite for upper extremity function in stroke survivors. ${ }^{[16]}$ Therefore, it is important to evaluate the relationship between trunk impairment and upper extremity function in stroke survivors which may help in improving their ADL's by giving proper treatment. So, in order to provide effective rehabilitation for stroke patients, considering the available information, this study was designed to find the relationship between trunk impairment and upper extremity function, and its impact on activities of daily living in chronic stroke survivors.

\section{MATERIALS AND METHODS}

An observational study was conducted on chronic stroke survivors, Mangalore, India. The participants were included for the study based on the criteria's; single episode of stroke either ischemic or haemorrhagic, duration of the condition within 3 months to 1 year, age group 40-80 years, MMS score of 23 or above, both males and females. Any neurological disease other than stroke, medically unstable patients, any musculoskeletal disorders affecting shoulder and trunk, patients with impaired cognitive status, visual or auditory impairments, and patients with hemodynamic instability were excluded from the study. Outcome measures used were, Trunk Impairment Scale to evaluate the trunk impairment, The Chedoke Arm and Hand Activity Inventory (version 
8) to evaluate the upper extremity function, and functional independence measure motor scoring to evaluate activities of daily living in patients with chronic stroke.

Based on a study conducted by Verheyden $\mathrm{G}$ et al ${ }^{[17]}$ assuming $\mathrm{r}=0.42$ with 95\% confidence interval, using the formula $\left(Z_{1}-\alpha / 2\right)^{2} \times\left(1-r_{x y}^{2}\right)$ divided by $r_{x y}^{2}$, the sample size estimated for the study is 17.5 approximately equal to 18 . Further assuming $10 \%$ of non-response rate the final sample size estimated for the study was 20 patients with chronic stroke. Approval was obtained from Institution Ethical Committee (IEC) and before the study begins, informed written consent was obtained from all the participants.

\section{Procedure}

Demographic data of all the participants were recorded for the study. Standard information's regarding trunk impairment scale, chedoke arm and hand activity inventory and functional independence measure were given to all the participants before evaluating trunk impairment, upper extremity function and activities of daily living using these outcome measures.

\section{Trunk Impairment Scale (TIS)}

This Scale was used to evaluate the trunk function in patients with neurological impairments. TIS consists of 17 parameters under 3 components, two of them are used to assess static and dynamic sitting balance and the third component included coordination of trunk. Starting position for all the items were in sitting, thighs horizontal and feet flat on support, knee $90^{\circ}$ flexed, on back support, hand and forearm resting on the thighs. Verbal and nonverbal (demonstration) instructions can be given to the participants. There are 3 trials for each item. The best performance among them will be scored. The maximal score for the static and dynamic sitting balance and coordination subscale is 7,10 and 6 points, respectively. The total score ranges from 0 (worst performance) to a maximum of 23 (best performance). ${ }^{[18,19]}$

\section{Chedoke Arm and Hand Activity Inventory (CAHAI-8)}

It is a reliable and valid functional assessment tool (ICC $=0.97, \mathrm{r}>0.90$ ) used to evaluate the recovering arm and hand function after stroke. It consists of 8 functional items that are non-gender specific, involve both upper limbs, and incorporates a range of movements and grasps that reflect stages of motor recovery following stroke. Each item of the CAHAI is scored on a 7-point quantitative scale, similar to the scale used in the Functional Independence Measure with minimum score 8 and maximum score 56. Higher scores indicating greater functional independence. [20,21]

\section{Functional Independence Measure (FIM- Motor)}

This scale was used to assess the level of a patient's disability indicates the burden of caring for them and items are scored on the basis of how much assistance is required for the individual to perform activities in their daily living. The Motor-FIM consist of 13 items which assesses four areas of function that include Self-care, Sphincter control, Transfers and Locomotion. Each item on the FIM is scored on a 7-point scoring scale, and the score indicates the amount of assistance required to perform each item $(1=$ total assistance, $7=$ total independence). The ratings are based on performance rather than capacity. The total score ranges from $13-$ 91, where 13 represents complete dependence/total assistance and 91 represents complete independence. ${ }^{[22,23]}$

\section{Statistical analysis}

Demographic characteristics of the participants including age, height, weight and BMI were analysed by descriptive statistics. Karl Pearson's correlation coefficient was used to find the relationship between trunk impairment and upper 
Ludhiya Baby et.al. Relationship between trunk impairment and upper extremity function, and its impact on activities of daily living in chronic stroke survivors.

extremity functional, and the impact of both components on activities of daily living in chronic stroke patients. A statistical package SPSS ver.20.0 was used for analysis and 'p' value $\leq 0.05$ was considered as significant.

\section{RESULT}

Among 20 participants with age 40 80 years $(64 \pm 10.5), 65 \%(n=13)$ were males and $35 \% \quad(n=7)$ were females. Stroke patients included in this study were of ischemic stroke (85\%) and haemorrhagic stroke (15\%), with a mean duration of $6.3 \pm 4.1$ months. Among them $80 \%(n=16)$ were with right side paresis and $20 \%(\mathrm{n}=4)$ were of left side paresis. While analysing TIS score, CAHAI-8 score and FIM-M score, the Mean and standard deviation obtained were $13.64 \pm 3.63,35.95 \pm 6.39$ and $53.10 \pm 8.12$ respectively. (Table 1 )

Table 1. Characteristics of the participants $(n=20)$

\begin{tabular}{|lccc|}
\hline Variables & \multicolumn{1}{c|}{$\mathbf{n ( \% )}$} & Mean(SD) & Range \\
\hline Gender(M/F) & $13(65 \%) / 7(35 \%)$ & & \\
Age(years) & & $64(10.5)$ & $42-80$ \\
Side of paresis (R/L) & $16(80 \%) / 4(20 \%)$ & & \\
Stroke type (ischemic/haemorrhagic) & $17(85 \%) / 3(15 \%)$ & & \\
Post Stroke Duration (months) & & $6.3(4.1)$ & $2-12$ \\
TIS score & & $13.64(3.63)$ & $7-20$ \\
CAHAI-8 score & $35.95(6.39)$ & $27-48$ \\
FIM-M score & $53.10(8.12)$ & $41-69$ \\
\hline SD: Standard deviation; TIS: Trunk Impairment Scale; CAHAI-8: Chedoke Arm and Hand Activity Inventory; FIM- M: Functional \\
Independence Measure - motor score.
\end{tabular}

Further, using Karl Pearson's Correlation coefficient, it was observed that moderate positive correlation exists between TIS and CAHAI-8 $(\mathrm{r}=0.662)$ which was highly significant at 0.01 level. (Table 2, Figure 1)

Table 2. Correlation between trunk impairment and upper extremity function.

\begin{tabular}{|c|c|c|}
\hline \multicolumn{3}{|r|}{ CAHAI-8 } \\
\hline TIS & $\begin{array}{l}\text { Pearson Correlation } \\
\text { Sig. (2-tailed) } \\
\mathrm{N}\end{array}$ & $\begin{array}{l}.662^{* *} \\
.001 \\
20\end{array}$ \\
\hline \multicolumn{3}{|c|}{$\begin{array}{l}\text { ** Correlation is significant at the } 0.01 \text { level (2-tailed). TIS: } \\
\text { Trunk Impairment Scale; CAHAI-8: Chedoke Arm and Hand } \\
\text { Activity Inventory. }\end{array}$} \\
\hline
\end{tabular}

While correlating FIM-M with TIS and CAHAI-8, strong positive correlation was resulted between TIS and FIM-M ( $\mathrm{r}=$ 0.886 ), were moderate positive correlation was noted between CAHAI-8 and FIM-M (r $=0.646)$ with significant level at 0.01. (Table 3, Figure 2)

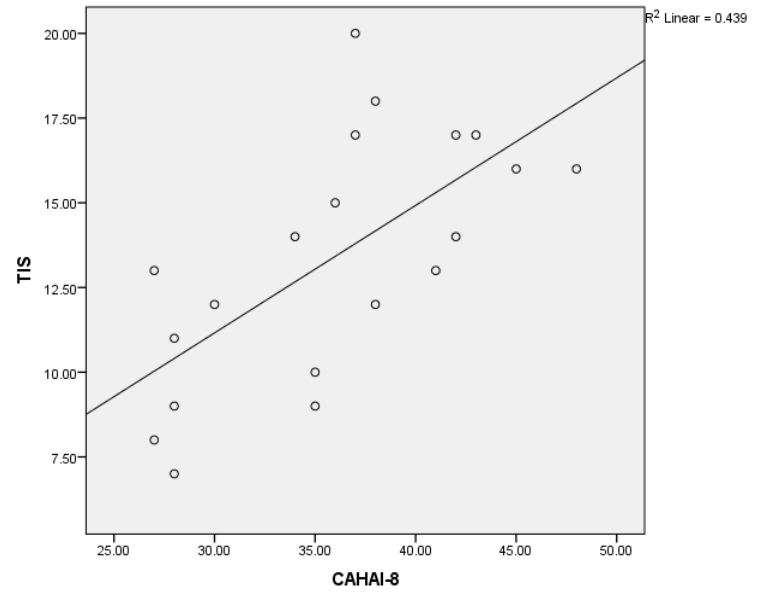

Figure 1: Relationship between trunk impairment and upper extremity function.
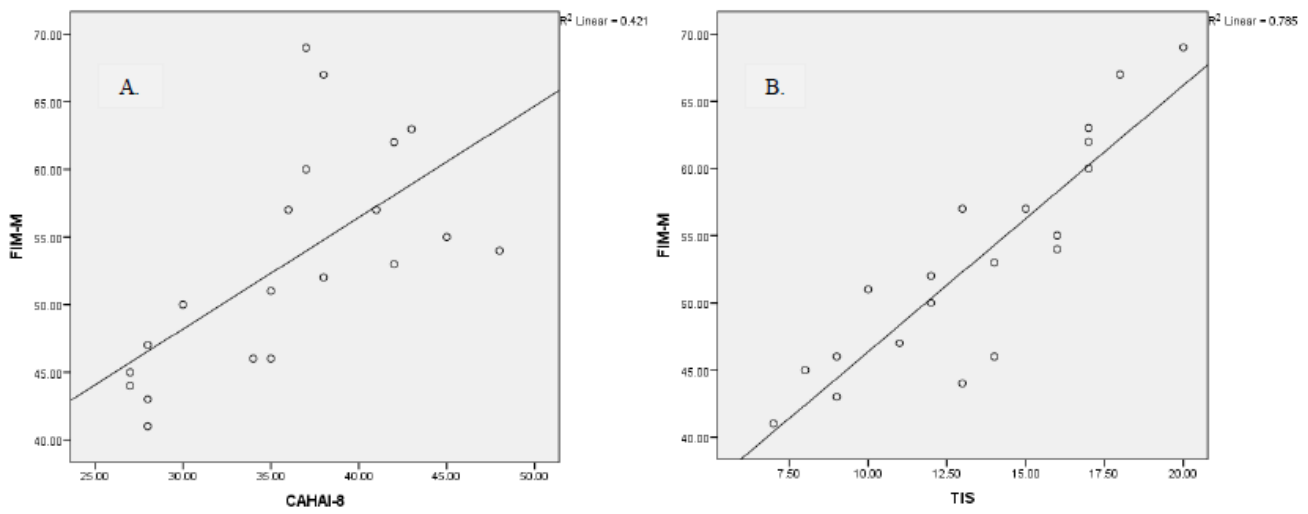

Figure 2: A) Relationship between upper extremity function and activities of daily living, B) relationship between trunk impairment and activities of daily living. 
Ludhiya Baby et.al. Relationship between trunk impairment and upper extremity function, and its impact on activities of daily living in chronic stroke survivors.

Table 3. Correlation of trunk impairment and upper extremity function with activities of daily living.

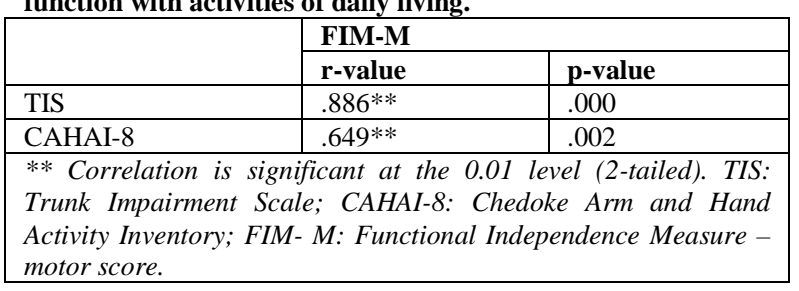

\section{DISCUSSION}

An observational study was conducted on chronic stroke survivors in order to determine the relationship between trunk impairment and upper extremity function and, to find its impact on activities of daily living in patients with chronic stroke. Stroke is considered as a major cause of disability in worldwide. ${ }^{[24]}$ Patients with stroke may experience muscle weakness, fatigue, reduced postural control and difficulty in movements. Studies shows that trunk performance and upper extremity function are the most common and challenging impairments seen in stroke patients. These impairments may limit the stroke survivor's ability to perform their activities of daily living. So, this study was designed as an attempt to find the relationship between trunk impairment and upper extremity function in chronic stroke survivors and to determine their effect on activities of daily living.

20 chronic stroke survivors with age group between $40-80$ years were included in this study. We had included both ischemic and haemorrhagic stroke survivors in this study. Trunk impairment, upper extremity function and activities of daily living of all the participants were determined using trunk impairment scale, Chedoke arm and hand activity inventory scale (version 8) and functional independence measure - motor scoring scale. The data obtained from each participants using the outcome measures were analysed using Karl Pearson's correlation coefficient.

While analyzing the relationship between trunk impairment and upper extremity function, the result shows that moderate positive correlation exists between TIS and CAHAI-8 score. This result indicates that if the trunk function gets reduced in stroke patients, it will also reduce the upper extremity function of patients with chronic stroke. Similar to our study Wee et al. in their study on stroke patients and healthy controls suggest that, trunk restraint may improve the upper extremity function in both stroke patients and in healthy groups. ${ }^{[11]}$ This shows that improved trunk stability has an effect on upper extremity stability, which could help its function with proper reaching and grasping of the objects. Likhi et al. also suggest that, the functional independent of stroke patients are closely related to trunk impairment followed by upper extremity impairments. ${ }^{[4]}$ This may be due to the integral role of trunk in postural stability which is essential to perform controlled movement of upper extremity on each task performance. So proper trunk stability rehabilitation in the acute phase of stroke could avoid the compensatory strategy which may reflect to abnormal upper extremity movements and could reduce the recovery period in stroke survivors.

In order to find the impact of trunk impairment on activities of daily living in chronic stroke survivors, trunk impairment scores and functional independence measure - motor scoring of the participants were correlated. The result obtained suggest that, a strong positive correlation exist between TIS and FIM-M score. This result indicates that, if the trunk function gets affect or reduced, it could severely affect activities of daily living in patients with chronic stroke. In accordance with our study Karatas et al in their study on unihemispheric stroke patients reported that, even a mild impairment on trunk muscle could affect the balance and functional ability in unihemispheric stroke patients. [25] Similarly, Hsieh et al on their study on stroke patients reveals that, level of trunk impairment could strongly affect ADL function in stroke patients. So, early assessment and management of trunk control is essential to increase the activity level in stroke patients. ${ }^{[7]}$ It may be due to 
the known fact that trunk is the key factor that stabilize the body during functional movements and any impairment to this stability will affect body to control its movements during each task. This may limit the stroke survivors from performing their daily living activities.

While analysing the impact of upper extremity function on activities of daily living in chronic stroke survivors, it was noted that, moderate positive correlation exists between CAHAI-8 and FIM-M. This indicates that, when upper extremity function in chronic stroke survivors get reduced, their functional activity level of daily living will also get reduced. This may be due to the reason that, most of our fundamental daily activities like eating, dressing, washing and grooming requires active functioning of upper extremities. So, any impairment to the function of upper extremities could affect all these daily activities. In accordance with this Fortini et al suggested that, upper extremity function should be considered as an important target for clinical interventions to improve the activity and participation level in chronic stroke patients. ${ }^{26]}$

Our study reveals that, increased trunk stability will be a promising adjunct to improve the upper extremity function, as it shows a strong correlation in chronic stroke survivors. Considering these factors in rehabilitation of stroke patients will improve their activity level in daily living and may also help to reduce the recovery period.

\section{Limitation}

This study has not evaluated the rehabilitation period received by the participants include in the study. This may alter the activity level of each participant. Another limitation of this study was the small sample size. Further scope of this study could be on rehabilitation-based evaluation in chronic stroke survivors with large sample size.

\section{CONCLUSION}

Our study concludes that, a moderate positive correlation exists between trunk impairment and upper extremity function in chronic stroke survivors. The study also reveals that, both trunk impairment and upper extremity function has strong and moderate correlation on their activities of daily living.

\section{ACKNOWLEDGEMENT}

We express our sincere gratitude and acknowledge the support of statistician and all the participants who had participated in this study.

\section{Conflict of Interest: None}

\section{Source of Funding: None}

\section{Ethical Approval: Approved}

\section{REFERENCES}

1. Eraifej J, Clark W, France B, Desando S, Moore D. Effectiveness of upper limb functional electrical stimulation after stroke for the improvement of activities of daily living and motor function: a systematic review and meta-analysis. Syst Rev. 2017 Feb 28;6(1):1-21.

2. Bonita R, Beaglehole R. Stroke prevention in poor countries: time for action. Stroke. 2007 Nov;38(11):2871-2.

3. El-Nashar H, ElWishy A, Helmy H, ElRwainy R. Do core stability exercises improve upper limb function in chronic stroke patients?. Egypt J Neurol Psychiatr Neurosurg. 2019 Dec;55(1):1-9.

4. Likhi M, Jidesh VV, Kanagaraj R, George JK. Does trunk, arm, or leg control correlate best with overall function in stroke subjects? Top Stroke Rehabil. 2013 Jan-Feb;20(1):62-7.

5. Jorgensen HS, Nakayama $H$, Raaschou HO, Vive-Larsen J, Stoier M, Olsen TS. Outcome and time course of recovery in stroke. Part II: Time course of recovery. The Copenhagen Stroke Study. Arch Phys Med Rehabil. 1995 May;76(5):399-405.

6. Verheyden G, Nieuwboer A, De Wit L, Feys H, Schuback B, Baert I, Jenni W, 
Schupp W, Thijs V, De Weerdt W. Trunk performance after stroke: an eye catching predictor of functional outcome. J Neurol Neurosurg Psychiatry. 2007 Jul;78(7): 694-8.

7. Hsieh CL, Sheu CF, Hsueh IP, Wang CH. Trunk control as an early predictor of comprehensive activities of daily living function in stroke patients. Stroke. 2002 Nov;33(11):2626-30.

8. Wade DT, Skilbeck CE, Hewer RL. Predicting Barthel ADL score at 6 months after an acute stroke. Arch Phys Med Rehabil. 1983 Jan;64(1):24-8.

9. Liao CF, Liaw LJ, Wang RY, Su FC, Hsu AT. Electromyography of symmetrical trunk movements and trunk position sense in chronic stroke patients. J Phys Ther Sci. 2015 Sep;27(9):2675-81.

10. Franceschini M, La Porta F, Agosti M, Massucci M; ICR2 group. Is healthrelated-quality of life of stroke patients influenced by neurological impairments at one year after stroke? Eur J Phys Rehabil Med. 2010 Sep;46(3):389-99.

11. Wee SK, Hughes AM, Warner M, Burridge JH. Trunk restraint to promote upper extremity recovery in stroke patients: a systematic review and metaanalysis. Neurorehabil Neural Repair. 2014 Sep;28(7):660-77.

12. Yang SH, Chung EJ, Lee J, Lee SH, Lee BH. The Effect of Trunk Stability Training Based on Visual Feedback on Trunk Stability, Balance, and Upper Limb Function in Stroke Patients: A Randomized Control Trial. Healthcare (Basel). 2021 May 2;9(5):532.

13. Kanekar N, Aruin AS. Aging and balance control in response to external perturbations: role of anticipatory and compensatory postural mechanisms. Age (Dordr). 2014 Jun;36(3):1067-1077.

14. Olsen TS. Arm and leg paresis as outcome predictors in stroke rehabilitation. Stroke. 1990 Feb;21(2):247-51.

15. Rhoda A, Mpofu R, De Weerdt W. Activity limitations of patients with stroke attending out-patient facilities in the Western Cape, South Africa. S. Afr. J. Physiother. 2011 Jan 5;67(2):16-22.
16. Cirstea MC, Levin MF. Compensatory strategies for reaching in stroke. Brain. 2000 May;123 ( Pt 5):940-53.

17. Verheyden G, Vereeck L, Truijen S, Troch M, Herregodts I, Lafosse C, Nieuwboer A, De Weerdt W. Trunk performance after stroke and the relationship with balance, gait and functional ability. Clin Rehabil. 2006 May;20(5):451-8.

18. Di Monaco M, Trucco M, Di Monaco R, Tappero R, Cavanna A. The relationship between initial trunk control or postural balance and inpatient rehabilitation outcome after stroke: a prospective comparative study. Clin Rehabil. 2010 Jun;24(6):543-54.

19. Verheyden G, Nieuwboer A, Mertin J, Preger R, Kiekens C, De Weerdt W. The Trunk Impairment Scale: a new tool to measure motor impairment of the trunk after stroke. Clin Rehabil. 2004 May;18(3):326-34.

20. Harris JE, Eng JJ. Individuals with the dominant hand affected following stroke demonstrate less impairment than those with the nondominant hand affected. Neurorehabil Neural Repair. 2006 Sep;20(3):380-9.

21. Barreca SR, Stratford PW, Lambert CL, Masters LM, Streiner DL. Test-retest reliability, validity, and sensitivity of the Chedoke arm and hand activity inventory: a new measure of upper-limb function for survivors of stroke. Arch Phys Med Rehabil. 2005 Aug;86(8):1616-22.

22. Yamamoto H, Takeda K, Koyama S, Morishima K, Hirakawa Y, Motoya I, Sakurai H, Kanada Y, Kawamura N, Kawamura M, Tanabe S. Relationship between upper limb motor function and activities of daily living after removing the influence of lower limb motor function in subacute patients with stroke: A crosssectional study. Hong Kong J Occup Ther. 2020 Jun;33(1):12-17.

23. Santos RSD, Dall'alba SCF, Forgiarini SGI, Rossato D, Dias AS, Forgiarini Junior LA. Relationship between pulmonary function, functional independence, and trunk control in 
Ludhiya Baby et.al. Relationship between trunk impairment and upper extremity function, and its impact on activities of daily living in chronic stroke survivors.

patients with stroke. Arq Neuropsiquiatr. 2019 Jul 15;77(6):387-392.

24. Feigin VL, Lawes CM, Bennett DA, Anderson CS. Stroke epidemiology: a review of population-based studies of incidence, prevalence, and case-fatality in the late 20th century. Lancet Neurol. 2003 Jan;2(1):43-53.

25. Karatas M, Cetin N, Bayramoglu M, Dilek A. Trunk muscle strength in relation to balance and functional disability in unihemispheric stroke patients. Am J Phys Med Rehabil. 2004 Feb;83(2):81-7.

26. Faria-Fortini I, Michaelsen SM, Cassiano JG, Teixeira-Salmela LF. Upper extremity function in stroke subjects: relationships between the international classification of functioning, disability, and health domains. J Hand Ther. 2011 Jul-Sep; 24(3): 257-64.

How to cite this article: Baby L, Joy A, Ranjith KV. Relationship between trunk impairment and upper extremity function, and its impact on activities of daily living in chronic stroke survivors. International Journal of Science \& Healthcare Research. 2021; 6(4): 220-227. DOI: https://doi.org/10. 52403/ijshr.20211032 